Research

\title{
Suicide ideation and psychosocial distress among refugee adolescents in Bidibidi settlement in West Nile, Uganda
}

\author{
Paul Bukuluki $^{1} \cdot$ Peter Kisaakye $^{2} \cdot$ Symon Peter Wandiembe ${ }^{3} \cdot$ Samuel Besigwa $^{1}$
}

Received: 21 August 2021 / Accepted: 23 September 2021

Published online: 04 October 2021

(c) The Author(s) $2021 \quad$ OPEN

\begin{abstract}
This study investigated the factors associated with suicidal ideation and psychological distress among Sudanese refugees (aged 10-19 years) in Bidibidi refugee settlement, Yumbe district, Uganda. The analysis is based on cross-sectional data collected as part of the implementation of a project on sexual and reproductive health in Bidibidi refugee settlement. Data were collected from 284 South Sudanese adolescents in July 2020. We estimated the prevalence of psychological distress and suicidal ideation, and their associated profiles. Odds ratios and their $95 \%$ Confidence Intervals based on a logistic regression model were used to assess the effect of different potential factors on the risk profiles for suicidal ideation and psychological distress. The prevalence of psychological distress (on KS- 6 scale) was estimated to be $12.3 \%$ (95\%Cl: 8.7, 16.7\%). The risk for psychological distress is low among male adolescents ( $\mathrm{AOR}=0.51 ; 95 \% \mathrm{Cl}: 0.23,1.02$ ), older adolescents, $(\mathrm{AOR}=0.12 ; 95 \% \mathrm{Cl}: 0.04,0.40)$, and adolescents with a friend or family members they can confide in ( $A O R=0.33 ; 95 \% \mathrm{Cl}: 0.11,0.96)$. Both suicidal ideation and psychological distress are very high among the female adolescents. Familial and individual interventions can be potentially useful for female adolescents who have a high risk of suicide and psychological distress.
\end{abstract}

Keywords Adolescents · Bidibidi · Psychological distress · Refugees · Suicide attempt · Suicide ideation · Uganda

$\begin{array}{ll}\text { Abbreviations } \\ \text { CAPI } & \text { Computer Assisted Personal Interviewing } \\ \text { OPM } & \text { Office of the Prime Minister } \\ \text { RWC } & \text { Refugee Welfare Council } \\ \text { SA } & \text { Suicide Attempt(s) } \\ \text { SI } & \text { Suicide Ideation(s) } \\ \text { UNHCR } & \text { United Nations High Commissioner for Refugees } \\ \text { WHO } & \text { World Health Organisation }\end{array}$

$\triangle$ Peter Kisaakye, pkisaakye@gmail.com; Paul Bukuluki, pbukuluki@gmail.com; Symon Peter Wandiembe, symon.wand@yahoo.com; Samuel Besigwa, akiikibesigwasam@gmail.com | 'Department of Social Work and Social Administration, School of Social Sciences, Makerere University, Kampala, Uganda. ${ }^{2}$ Department of Population Studies, School of Statistics and Planning, Mathematics Building, Makerere University Main Campus, P O Box 7062, Kampala, Uganda. ${ }^{3}$ Department of Statistical Methods, School of Statistics and Planning, Makerere University, Kampala, Uganda.

Discover Psychology ～～（2021) 1:3 https://doi.org/10.1007/s44202-021-00003-5 


\section{Introduction}

Suicide ideation (SI) or suicide attempt (SA) remain a public health concern [1]. The World Health Organization (WHO) estimates about 800,000 deaths from suicide related causes annually [2]. Suicide has also been reported as a leading cause of death among adolescents and youth living in refugee settings, particularly in the age group 15-29 years [1, 3]. Adolescents are generally most vulnerable to suicide as this stage involves highly continuous mental and physical developments $[4,5]$. Despite the alarming situation about suicidality, there is limited knowledge on the risk of suicide behaviors among vulnerable populations such as adolescent refugees [1, 3, 6, 7]. Moreover, there is limited literature on SI and SA among vulnerable populations such as refugee adolescents [1,3].

Data from middle-school immigrant adolescents from North-Eastern France revealed a two-time higher risk of experiencing SI and SA than non-migrants [3]. This implies that educated people may be less likely to experience $\mathrm{SI}$ and SA because of an increase in social mobility [8]. A recent study consisting of 251 emerging adults from two universities in South-West Nigeria revealed that an increase in family support leads to a decrease in SI and SA due to a decrease in depression [1]. According to Olatunji and colleagues, family support is part of social support that helps in providing material, financial and emotional support [1].

Previous research estimated suicide ideation to be $21 \%$ in a rural Ugandan population [9]. Others estimated suicide ideation and suicide attempt to be 12 and $6 \%$ among respondents aged 18 and above in Gulu, Amuru and Nwoya districts in Uganda [7]. A population-based study conducted in post-conflict Northern Uganda revealed that suicidality was more prevalent among individuals with a depression disorder and females [7].

The literature points to several factors associated with suicide ideation (SI) or suicide attempt (SA). These include feeling or being lonely [10], discrimination [11], financial constraints [3], anger [12], mental illness [7, 13], political tyranny [5], depression [14, 15], alcohol abuse [16], substance abuse [17, 18], unemployment [19], stress or posttraumatic stress disorder [20,21], acculturation related stress [6], war [22], trauma [23], isolation [24], family instability or conflicts [12,25], history of suicide behaviours [26], violence [27], or gender-based violence [28, 29], sexual abuse [30], child abuse or bullying [31], and not having a close friend [32].

There is need to identify the risk factors associated with SI and SA among vulnerable populations such as refugee adolescents since they are of different education, behavioral, social, health, employment and substance use factors. Suicide ideation or attempt behaviors among refugee adolescents remain a complex dimension to understand [3]. Understanding the risk factors associated with SI and SA may help in devising prevention strategies against experiencing SI and SA. Previous research $[33,34]$ has observed that refugee adolescents are more likely to have parents or guardians with low education, poor health and socioeconomic background as well as disjointed families which are probable predictors of SI and SA [35].

The aim of this study was to investigate the prevalence and risk factors of suicide ideation (SI) and psychosocial distress among adolescents in Bidibidi refugee settlement in Uganda. We focus on adolescent refugees who are mostly immigrants because previous studies have reported a higher rate of suicide ideation and attempt among immigrants than native populations $[3,5,6,14]$ —calling for selective preventive strategies to assist vulnerable groups needed [3]. This study was conducted during the COVID-19 pandemic when there were restrictions on movements, which could have affected living conditions of people. For example, refugees in Uganda are allowed to move in and out of their refugee camps to engage in commercial and other activities [36, 37]. However, travel restrictions, could have had a negative impact on the welfare of refugees especially for those who could not move either to meet their families or engage in any commercial and social activities outside refugee settlements [38].

\subsection{Theoretical framework}

This paper draws on the interpersonal theory of suicidal behaviour (IPTS) [39]. The IPTS is one of the most theories used to understand suicide behaviour [40]. The theory posits that two conditions (proximal factors) must be present for suicide ideation to happen: perceived burdensomeness and thwarted belongingness). According to the theory, people get suicidal ideations when their perceived level of burdens (perceived burdensomeness) and feeling lonely increases thwarted belongingness). Perceived burdensomeness refers to when someone thinks their existence is a burden to people around them such as family members or friends. Thwarted belongingness refers to when thinks they do not belong to any group or family or friends [41,42]. As suicidal ideations increase, people tend to carry out 
suicide attempts [43]. The implication of this is that suicide attempt can only happen after suicide ideation. Joiner and colleagues argue that people attempt suicide after positioning themselves in a state where they have overcome the fear of injury, death or even pain [44]. Drawing on the life course theory, suicide attempts may also be caused by other environmental or social factors. For example, the risk of committing a suicide among adolescents may increase due to death of a parent, family conflict, limited parental support which may limit progress to adult life [45-47].

Based on the literature, we hypothesize that adolescents who have a friend or family member to confide in were less likely to experience suicide ideation or psychosocial distress. Adolescents who are aware of or have ever accessed psychosocial support were less likely to experience suicide ideation or psychosocial distress.

\section{Data and methods}

This study investigated the factors associated with suicidal ideation and psychological distress among 281 Sudanese refugees (aged 10-19 years) in Bidibidi refugee settlement, Yumbe district in Uganda. The site was chosen because it is the largest refugee settlement in Uganda. It hosts largely South Sudanese refugees, primarily from the Equatorial region. The analysis is based on data collected during a cross-sectional study on adolescent sexual, reproductive health and psychosocial wellbeing. This study was conducted by Makerere University using a team of trained researchers based in Yumbe district where the Bidibidi refugee settlement is located. Given that it was during the COVID-19 pandemic, the research team had to strictly observe all COVID-19 Standard Operating procedures (ensuring wearing of masks for both the interviewers and respondents, sanitizing and observing social distancing) as recommended by the World Health Organization [48] to ensure no harm to the participants and the research team. A structured questionnaire was developed based on the study objectives, and data were collected using the Computer Assisted Personal Interviewing (CAPI) technology.

A probability-based sample approach was employed to select 300 eligible adolescents for interviews. The computation of the sample size to assure estimation of adolescents was based on the sample size tables by Krejcie and Morgan [49]. From on literature [7], we assumed suicidal attempt among adolescents to be $10 \%$. A sample size of 300 adolescents was sufficient to assure estimation of this proportion with $25 \%$ relative standard error and $95 \%$ certainty, while allowing for non-response rate of $5 \%$ and cluster design effect of 2.0 .

A two-stage cluster sample was taken. In the first stage, a list of all blocks (a block is an equivalent to a village) in the settlement and their sizes (number of households) were obtained from the settlement commandant's office. A probability proportional to size sample of 30 blocks was taken. Within each selected block, the research team worked with Refugee Welfare Council (RWC) who facilitated the process of identifying households with at least one adolescent (10-19 years). A numbered list of households with adolescents within each sampled block was generated and a systematic sample of ten taken. The total of eligible households, $\mathrm{N}$, divided by 10 was used as a sampling interval in each block. The selection of the first household was automated in the CAPI. Within each sampled household, a list of all adolescents was generated and numbered. A lottery method was used to select one adolescent for the interview.

Out of the estimated total sample size of 300 adolescents (10-19 years), only 284 adolescents responded to the interview - giving a response rate of $95 \%$. Permission to conduct the study was granted by the School of Social Sciences Research Ethics Committee at Makerere University. Each respondent was interviewed separately, with permission from the participant and their parent or guardian(s) (consent and assent) sought through the consenting process facilitated by an informed consent form. The interview duration ranged from $45 \mathrm{~min}$ to $1 \mathrm{~h}$.

The depressive symptoms were assessed using KS-6 scale, a well-studied and validated scale used for adolescents (Kessler et al. 2002; Richwood et al. 2015). The score sum ranged from 0 to 24. Similar to the study by Richwood et al. 2015, a cutoff point of 10 was used to differentiate depressed versus non-depressed individuals. Cronbach's alpha reliability coefficient in our sample was estimated as 0.78 .

Variables that were used in our analysis included socio-demographic characteristics: age (10-12, 13-15, 16-19), education (primary, secondary), religion (Anglican, Catholic, Other), employment status (employed, not employed, student), HIV/AIDS (negative, positive, do not know), alcohol abuse (no, yes), drug and substance abuse (no, yes), have a friend or family member you can confide in (no, yes), aware of places for psychosocial support (no, yes) and ever accessed psychosocial support (no, yes). The questions on suicidality and psychosocial support included: (a) Have you ever had thoughts of killing yourself in the last 4 weeks?, (b) Have you ever had thoughts of killing yourself in the last one week?, (c) Have you tried killing yourself in the last six months? (d) Do you have hope for the future?, and experience of psychosocial distress. Responses to each of the questions were a yes or no. 
Data analysis was performed using Stata software version 15.0 (Stata Corporation, College Station, TX, USA). Descriptive statistics including percentages and frequencies were used to summarize categorical variables. A binary logistic regression model was used to assess the factors associated with suicide ideation and psychosocial distress.. The results are reported as proportions, with odds ratios (OR) and their $95 \%$ confidence intervals $(95 \% \mathrm{Cl})$. Only factors with log likelihood ratio test $\mathrm{p}$-value of at most 0.25 in the first model were included in the second model.

\section{Results}

\subsection{Characteristics of respondents}

Of the 281 adolescents that participated in the study, $69 \%$ were male, $12.5 \%$ were aged below 12 years and $53 \%$ were aged $13-15$ years (Table 1 ). Ninety four percent (94.2\%) had only primary school level education and $51.2 \%$ ( $74 \%$ of the girls and $41 \%$ of the boys) were currently schooling. All the adolescents except three girls were married or cohabiting. About $47 \%$ reported to have ever tested for HIV, of which only one self-reported to be HIV positive. Only $1.4 \%$ reported alcohol abuse and $1.4 \%$ had ever used illicit substances. Of those out of school, only $5 \%$ were employed. Over $90 \%$ reported to have friends in whom they could confide in about relationship and psychosocial issues, $33.5 \%$ were aware of a place to seek psychosocial support and counselling and overall, $32.4 \%$ had ever sought psychosocial support and counselling services.

\subsection{Prevalence of suicide ideation and psychological distress}

The prevalence of suicidal ideation in the past four weeks was estimated as $5.3 \%$ (95\% Cl: 3.1, 7.4\%) while suicidal attempt in the last six months preceding the study was reported by $0.7 \%(95 \% \mathrm{Cl}: 0.3,1.2 \%)$ of the adolescents. The prevalence of both ideation and attempt among female adolescents was more than twice the prevalence among the female adolescents. Prevalence of suicidal ideation was $12.6 \%$ among girls and $3.6 \%$ among the boys while a suicide attempt was $3.5 \%$ and $0.9 \%$ among the female and adolescents, respectively. The prevalence of psychological distress (on KS-6 scale) was estimated to be $12.1 \%$ (95\% Cl: $8.7,16.7 \%)$. This was dominated by lack of hope in the future, estimated at $11.7 \%(95 \% \mathrm{Cl}$ : $8.1,15.9 \%)$. Similar to suicide ideation, more female than male adolescents reported psychological distress (18.6 vs. 9.2\%).

\subsection{Factors associated with suicidal ideation or psychological distress}

At univariate analysis (Table 2), male adolescents (OR $0.20 ; 95 \% \mathrm{Cl}: 0.07,0.60$ ) or having a friend/ family member/ relative to confide in was associated with $(\mathrm{OR} 0.16 ; 95 \% \mathrm{Cl}: 0.05,0.50)$ had less experience with suicide ideation in the last four weeks. On the other hand, males (OR $0.44 ; 95 \% \mathrm{Cl}: 0.21,0.92$ ) were less likely to be psychologically distressed compared to females. Adolescents in the aged $13-15$ years $(\mathrm{OR} 0.11 ; 95 \% \mathrm{Cl}: 0.04,0.29)$ and those aged $16-19$ years $(\mathrm{OR}=0.35 ; 95 \% \mathrm{Cl}$ : $0.14,0.84$ ) were all less likely to be associated with psychological distress compared to adolescents aged 10-12 years. Adolescents with some secondary school education (OR 3.98; 95\%Cl: 1.28, 12.33) were more likely to experience psychological distress than adolescents with primary education only. Similarly, adolescents who reported that they do not have hope in the future (OR $29.63 ; 95 \% \mathrm{Cl}: 12.16,72.20)$ were more likely to experience psychological distress than their counterparts.

Multivariable analysis based on a logistic regression model is presented in Table 3. At multivariate analysis, the risk for suicide ideation was low among male adolescents ( $A O R=0.16 ; 95 \% \mathrm{Cl}: 0.05,0.52)$ and adolescents with a friend or family members they can confide in $(A O R=0.14 ; 95 \% \mathrm{Cl}: 0.04,0.50)$. Similarly, the risk for psychological distress is low among male adolescents $(\mathrm{AOR}=0.51 ; 95 \% \mathrm{Cl}: 0.23,1.02)$, older adolescents as compared to those aged $10-12$ years $(\mathrm{AOR}=0.12$; $95 \% \mathrm{Cl}: 0.04,0.40$ ), and adolescents with a friend or family members they can confide in ( $\mathrm{AOR}=0.33 ; 95 \% \mathrm{Cl}: 0.11,0.96$ ).

\section{Discussion}

The results indicate a higher prevalence of suicide ideation and psychological distress among female than male refugee adolescents. Our findings are similar to those of Culbreth and colleagues who found a high occurrence of suicide ideation among female youth in Uganda [50]. For the Ugandan refugee context, this could among other factors be attributed to 
Table 1 Sample characteristics

\begin{tabular}{|c|c|c|c|c|c|c|}
\hline & \multicolumn{2}{|c|}{$\begin{array}{l}\text { Female adoles- } \\
\text { cents }\end{array}$} & \multicolumn{2}{|c|}{ Male adolescents } & \multicolumn{2}{|c|}{ Total } \\
\hline & $\mathrm{n}$ & $\%$ & $\mathrm{n}$ & $\%$ & $\mathrm{n}$ & $\%$ \\
\hline \multicolumn{7}{|l|}{ Age group } \\
\hline Very younger adolescents (10-12 years & 19 & 22.1 & 16 & 8.2 & 35 & 12.5 \\
\hline Younger adolescents (13-15 years old) & 44 & 51.2 & 105 & 53.8 & 149 & 53.0 \\
\hline Older adolescents (16-19 years old) & 23 & 26.7 & 74 & 37.9 & 97 & 34.5 \\
\hline \multicolumn{7}{|l|}{ Education level } \\
\hline Primary & 75 & 89.5 & 191 & 98.5 & 266 & 94.2 \\
\hline Secondary & 11 & 14.0 & 4 & 2.1 & 15 & 5.4 \\
\hline \multicolumn{7}{|l|}{ Religious affiliation } \\
\hline Anglican & 34 & 39.5 & 103 & 52.8 & 137 & 48.8 \\
\hline Catholic & 32 & 37.2 & 63 & 32.3 & 95 & 33.8 \\
\hline Other & 20 & 23.3 & 28 & 14.4 & 48 & 17.1 \\
\hline \multicolumn{7}{|l|}{ HIV/AIDS status (Self-reported) } \\
\hline I do not know & 53 & 61.6 & 96 & 49.2 & 149 & 53.0 \\
\hline Negative & 33 & 38.4 & 98 & 50.3 & 131 & 46.6 \\
\hline Positive & 0 & 0.0 & 1 & 0.5 & 1 & 0.4 \\
\hline \multicolumn{7}{|l|}{ Alcohol Abuse } \\
\hline No & 83 & 96.5 & 193 & 99.0 & 276 & 98.2 \\
\hline Yes & 3 & 3.5 & 1 & 0.5 & 4 & 1.4 \\
\hline \multicolumn{7}{|l|}{ Drug and substance abuse } \\
\hline No & 85 & 98.8 & 191 & 97.9 & 276 & 98.2 \\
\hline Yes & 0 & 0.0 & 4 & 2.1 & 4 & 1.4 \\
\hline \multicolumn{7}{|l|}{ Employment status } \\
\hline Employed & 0 & 0.0 & 6 & 3.1 & 6 & 2.1 \\
\hline Not Employed & 22 & 25.6 & 108 & 55.4 & 130 & 46.3 \\
\hline Student & 64 & 74.4 & 80 & 41.0 & 144 & 51.2 \\
\hline \multicolumn{7}{|l|}{ Have a friend/family member s/he can } \\
\hline No & 7 & 8.1 & 18 & 9.2 & 25 & 8.9 \\
\hline Yes & 78 & 90.7 & 177 & 90.8 & 255 & 90.7 \\
\hline \multicolumn{7}{|l|}{ Aware of places for psychosocial support } \\
\hline No & 53 & 61.6 & 133 & 68.2 & 186 & 66.2 \\
\hline Yes & 32 & 37.2 & 62 & 31.8 & 94 & 33.5 \\
\hline \multicolumn{7}{|l|}{ Ever accessed psychosocial support } \\
\hline No & 54 & 62.8 & 129 & 66.2 & 183 & 65.1 \\
\hline Yes & 31 & 36.0 & 60 & 30.8 & 91 & 32.4 \\
\hline \multicolumn{7}{|c|}{ Prevalence of suicide ideation and Psychological distress } \\
\hline Suicide ideation in last 4 weeks & 10 & 11.6 & 5 & 2.6 & 15 & 5.3 \\
\hline Suicide ideation in last one week & 7 & 8.5 & 1 & 0.5 & 8 & 3.0 \\
\hline Suicide ever attempted & 3 & 3.5 & 1 & 0.5 & 4 & 1.4 \\
\hline Suicide attempt in last six months & 1 & 1.2 & 1 & 0.5 & 2 & 0.7 \\
\hline Do not have hope for the future & 12 & 14.0 & 21 & 10.8 & 33 & 11.7 \\
\hline Psychological distress & 16 & 18.6 & 18 & 9.2 & 34 & 12.1 \\
\hline
\end{tabular}

the prevalence of other risk factors that affect female adolescents more than the males such as gender based violence $[28,29]$. Girls are for example likely to be subjected to limited mobility (control of mobility), sexual abuse and exploitation as well as burden of care reflected in taking on more domestic chores [30]. These are likely to affect the extent to which they can build social networks and have access to activities outside their immediate social environment. Our study also shows that adolescents with a friend or family member to confide in were less likely to experience suicide ideation in the last four weeks preceding the survey. This implies that having a limited social network of friends, relatives and 
Table 2 Univariate analysis: Multivariate analysis - logistic regression model of factors associated with suicide ideation or Psychological distress

\begin{tabular}{|c|c|c|c|c|c|c|c|}
\hline & \multirow[t]{2}{*}{$\mathrm{N}$} & \multicolumn{3}{|c|}{$\begin{array}{l}\text { Suicide ideation in last } \\
4 \text { weeks }\end{array}$} & \multicolumn{3}{|c|}{ Psychological distress } \\
\hline & & $\mathrm{n}$ & $\%$ & OR $(95 \% \mathrm{Cl})$ & $\mathrm{n}$ & $\%$ & OR $(95 \% \mathrm{Cl})$ \\
\hline \multicolumn{8}{|l|}{ Sex } \\
\hline Female adolescents & 86 & 10 & 11.6 & Ref & 16 & 18.6 & Ref \\
\hline Male adolescents & 195 & 5 & 2.6 & $0.2(0.07,0.6)^{*}$ & 18 & 9.2 & $0.44(0.21,0.92)^{*}$ \\
\hline \multicolumn{8}{|l|}{ Age group } \\
\hline Very younger adolescents ( $10-12$ years) & 35 & 2 & 5.7 & Ref & 12 & 34.3 & Ref \\
\hline Younger adolescents (13-15 years) & 151 & 7 & 4.6 & $0.8(0.16,4.04)$ & 8 & 5.3 & $0.11(0.04,0.29)^{*}$ \\
\hline Older adolescents (16-19 years) & 98 & 6 & 6.1 & $1.08(0.21,5.60)$ & 15 & 15.3 & $0.35(0.14,0.84)^{*}$ \\
\hline \multicolumn{8}{|l|}{ Education level } \\
\hline Primary & 269 & 15 & 5.6 & Ref & 30 & 11.2 & Ref \\
\hline Secondary & 15 & 0 & 0 & & 5 & 33.3 & $3.98(1.28,12.33)^{*}$ \\
\hline \multicolumn{8}{|l|}{ Religious affiliation } \\
\hline Anglican & 138 & 3 & 2.2 & Ref & 15 & 10.9 & Ref \\
\hline Catholic & 96 & 3 & 3.1 & $1.45(0.29,7.35)$ & 10 & 10.4 & $0.95(0.41,2.22)$ \\
\hline Other & 50 & 9 & 18 & $9.88(2.55,38.2)$ & 10 & 20 & $2.05(0.85,4.92)$ \\
\hline \multicolumn{8}{|c|}{ Have a friend/family member s/he can confide in } \\
\hline No & 25 & 5 & 20 & Ref & 6 & 24.0 & Ref \\
\hline Yes & 258 & 10 & 3.9 & $0.16(0.05,0.5)^{*}$ & 28 & 10.9 & $0.39(0.14,1.05)$ \\
\hline \multicolumn{8}{|c|}{ Aware of places for psychosocial support services } \\
\hline No & 188 & 12 & 6.4 & Ref & 25 & 13.3 & Ref \\
\hline Yes & 95 & 3 & 3.2 & $0.48(0.13,1.74)$ & 10 & 10.5 & $0.77(0.35,1.67)$ \\
\hline \multicolumn{8}{|c|}{ Ever accessed psychosocial support services } \\
\hline No & 185 & 11 & 5.9 & Ref & 23 & 12.4 & Ref \\
\hline Yes & 92 & 3 & 3.3 & $0.53(0.15,1.96)$ & 9 & 9.8 & $0.76(0.34,1.73)$ \\
\hline \multicolumn{8}{|l|}{ Do not have hope in the future } \\
\hline No & 251 & 12 & 4.8 & Ref & 14 & 5.6 & \\
\hline Yes & 33 & 3 & 9.1 & $2.00(0.53-7.43)$ & 21 & 63.6 & $29.63(12.16,72.2)^{*}$ \\
\hline Total & 284 & 15 & 5.3 & & 35 & 12.3 & \\
\hline
\end{tabular}

Table 3 Multivariate analysis - logistic regression model of factors associated with suicide ideation or Psychological distress

\begin{tabular}{|c|c|c|c|c|c|}
\hline & \multirow[t]{2}{*}{$\mathrm{N}$} & \multicolumn{2}{|c|}{ Suicide ideation in last 4 weeks } & \multicolumn{2}{|l|}{ Psychological distress } \\
\hline & & Adjusted OR $(95 \% \mathrm{Cl})$ & $p$-value & Adjusted OR $(95 \% \mathrm{Cl})$ & $\mathrm{p}$-value \\
\hline \multicolumn{6}{|l|}{ Sex } \\
\hline Female adolescents & 86 & & & & \\
\hline Male adolescents & 195 & $0.16(0.05,0.52)$ & 0.002 & $0.38(0.14,1.05)$ & 0.061 \\
\hline \multicolumn{6}{|l|}{ Age group } \\
\hline Very younger adolescents (10-12 years) & 35 & & & & \\
\hline Younger adolescents (13-15 years) & 151 & $1.17(0.19,7.12)$ & 0.862 & $0.23(0.05,1.03)$ & 0.05 \\
\hline Older adolescents (16-19 years) & 98 & $1.95(0.31,12.41)$ & 0.477 & $0.68(0.16,2.86)$ & 0.60 \\
\hline \multicolumn{6}{|l|}{ Education level } \\
\hline Primary & 269 & & & & \\
\hline Secondary & 15 & & & $0.44(0.06,3.38)$ & 0.43 \\
\hline \multicolumn{6}{|c|}{ Have a friend/family member $\mathrm{s} /$ he can confide in } \\
\hline No & 25 & & & & \\
\hline Yes & 258 & $0.14(0.04,0.5)$ & 0.003 & $0.46(0.12,1.72)$ & 0.25 \\
\hline \multicolumn{6}{|l|}{ Do not have hope in the future } \\
\hline No & 251 & & & & \\
\hline Yes & 33 & $1.32(0.28,6.27)$ & 0.729 & $29.5(10.81,50.56)$ & 0.00 \\
\hline
\end{tabular}


contact with family [50] increases loneliness and isolation. Other studies also have also established that suicide ideation and suicide attempt is associated with feeling or being lonely [10], isolation [24], and not having a close friend [32]. In our study, refugee adolescents who reported that they do not have hope in the future were more likely to experience psychological distress. It is important to note that because this study was conducted during the COVID-19 pandemic context, it may have exacerbated the loss of hope for the future and loss of contact with friends and family. For example, adolescents were no longer attending school, and this limits their interaction with their peers in the host population and at school. Similarly, COVID-19 control measures contributed to limited mobility for family members and friends who do not live in the refugee settlement but in cities in Uganda as urban refugees to visit their families and friends who live in refugee settlements. In Uganda, before COVID-19 restrictions were imposed, refugees were generally allowed to move in and outside the refugee camps and to even move to urban cities to work and engage in trade [36, 37]. So those who moved to urban areas for a number of months especially during the lockdown and stay home orders could not easily travel back to join their family members living in the refugee camps [38].

Loss of hope for the future among adolescent refugees tends to be linked to low disjointed families $[33,34]$ that comprise largely of women and children (World Bank, 2019). A household survey conducted by the World Bank in 2018 in refugee settlements in Uganda revealed that the women and children comprise about 82 percent of Uganda's overall refugee population while about 56 percent of refugees are below the age of 15 [35]. Families with adolescents in refugee settlements are also likely to have parents with low education, poor health and socioeconomic background which are likely to render adolescents susceptible to SI and SA [33].

Our results also show limited awareness where to access psychosocial support services among refugee adolescents and no gender differences were observed. They also show limited access and use of psychosocial support services. This is similar to results of a recent World Bank study in 11 refugee settlement (including Bidibidi settlement) that found that availability and access to mental health and psychosocial support services is low in refugee settlements in Uganda [35].

Adolescents with secondary education were more likely to experience psychological distress than adolescents with primary education. This could be explained by the fact that adolescents with secondary education tend to have higher expectations and if these are not met, they are likely to feel frustrated and unhappy compared to their counterparts with lower levels of education. Education has been shown to increase expectations for social mobility [8] and if these are not me it may increase risks of psychological distress.

\section{Conclusion}

Overall refugee adolescents, especially female adolescents are susceptible to suicidal ideations and attempts. The major risk factors associated with suicidal ideations and attempts include loneliness, isolation, not having friend or family member to confide in, having no hope for the future and limited or no access to mental health and psychosocial support services. Given these risk factors, it is important to ensure that mental health and psychosocial support is integrated in interventions and services targeting adolescents. These services can be integrated in school, out of school and in health services provided to adolescents. There is need to strengthen surveillance of suicidal ideations and attempts among all refugees particularly female adolescents. This more so, during global pandemic like COVID-19 that entail using measures that may further contribute to isolation, loneliness and loss of social contact, confinement at home within the camps and reduced mobility for adolescent refugees. We also recommend studies with a larger sample size to be carried out to further galvanize efforts geared towards generating evidence for advocacy for mental health and psychosocial services targeting adolescent refugees.

\section{Limitations}

There are three main limitations we note in this study. First, we are unable to generalize our results to the entire adolescent refugee populations because the results generated from the analyses in this study are based on a relatively smaller sample. Second, this study was conducted during the COVID-19 pandemic. For this reason, we were unable to incorporate qualitative and interactive interviews in our study, and last, the results we report in this study could have been affected by the effect of COVID-19 pandemic, but we were not able to control for that. 
Authors' contributions PB coordinated manuscript writing and discussed the results. PK conducted literature review and interpreted the results. SPW analysed the data and interpreted the findings. SB coordinated data collection. All authors read and approved the final manuscript.

Funding None.

Data availability The datasets used in this study are available from the corresponding author on reasonable request.

\section{Declarations}

Consent for publication Not applicable.

Competing interests The authors declare that they have no competing interests.

Open Access This article is licensed under a Creative Commons Attribution 4.0 International License, which permits use, sharing, adaptation, distribution and reproduction in any medium or format, as long as you give appropriate credit to the original author(s) and the source, provide a link to the Creative Commons licence, and indicate if changes were made. The images or other third party material in this article are included in the article's Creative Commons licence, unless indicated otherwise in a credit line to the material. If material is not included in the article's Creative Commons licence and your intended use is not permitted by statutory regulation or exceeds the permitted use, you will need to obtain permission directly from the copyright holder. To view a copy of this licence, visit http://creativecommons.org/licenses/by/4.0/.

\section{References}

1. Olatunji OA, Idemudia ES, Olawa BD. Family support, self-efficacy and suicidal ideation at emerging adulthood: a mediation analysis. Int J Adolesc Youth. 2020;25(1):920-31.

2. WHO. Suicide: one person dies every 40 seconds. 2019.

3. Chau K, Kabuth B, Chau N. Association between suicide ideation and attempts and being an immigrant among adolescents, and the role of socioeconomic factors and school, behavior, and health-related difficulties. Int J Environ Res Public Health. 2016;13(1070):1-15.

4. Swahn MH, Bossarte RM, Choquet M, Hassler C, Falissard B, Chau N. Early substance use initiation and suicide ideation and attempts among students in France and the United States. Int J Public Health. 2012;57(1):95-105.

5. Kien C, Sommer I, Faustmann A, Gibson L, Schneider M, Krczal E, Jank R, Klerings I, Szelag M, Kerschner B, et al. Prevalence of mental disorders in young refugees and asylum seekers in European Countries: a systematic review. Eur Child Adolesc Psychiatry. 2019;28:1295-310.

6. Lipsicas CB, Mäkinen IH. Immigration and suicidality in the young. Can J Psychiatry. 2010;55(5):274-81.

7. Mugisha J, Muyinda H, Kagee A, Wandiembe P, Mpugu SK, Vancampfort D, Kinyanda E. Prevalence of suicidal ideation and attempt: associations with psychiatric disorders and HIV/AIDS in post-conflict Northern Uganda. Afr Health Sci. 2016;16(4):1027-35.

8. Brown P. Education, opportunity and the prospects for social mobility. Br J Sociol Educ. 2013;34(5-6):678-700.

9. Sweetland AC, Norcini Pala A, Mootz J, Kao JCW, Carlson C, Oquendo MA, Cheng B, Belkin G, Wainberg M. Food insecurity, mental distress and suicidal ideation in rural Africa: Evidence from Nigeria, Uganda and Ghana. Int J Soc Psychiatry. 2018;65(1):20-7.

10. Dunlavy AC, Aquah EO, Wilson ML. Suicidal ideation among school-attending adolescents in Dar es Salaam, Tanzania. Tanzan J Health Res. 2015;17(1):1-9.

11. Sutter M, Perrin PB. Discrimination, mental health, and suicidal ideation among LGBTQ people of color. J Couns Psychol. 2016;63(1):98-105.

12. Ingabire CM, Richters A. Suicidal ideation and behavior among Congolese refugees in Rwanda: contributing factors, consequences, and support mechanisms in the context of culture. Front Psych. 2020;11(299):1-13.

13. Moore A, van Loenhout JAF, de Almeida MM, Smith P, Guha-Sapir D. Measuring mental health burden in humanitarian settings: a critical review of assessment tools. Glob Health Action. 2020;13(1):1783957.

14. Forte A, Trobia F, Gualtieri F, Lamis DA, Cardamone G, Giallonardo V, Fiorillo A, Girardi P, Pompili M. Suicide risk among immigrants and ethnic minorities: a literature overview. Int J Environ Res Public Health. 2018;15(1438):1-21.

15. Tol WA, Augustinavicius J, Carswell K, Brown FL, Adaku A, Leku MR, García-Moreno C, Ventevogel P, White RG, van Ommeren M. Translation, adaptation, and pilot of a guided self-help intervention to reduce psychological distress in South Sudanese refugees in Uganda. Glob Mental Health. 2018;5:e25.

16. Walsh SD, Edelstein A, Vote D. Suicidal Ideation and alcohol use among Ethiopian adolescents in Israel: the relationship with ethnic identity and parental support. Eur Psychol. 2012;17:131-42.

17. Hallgren KA, Ries RK, Atkins DC, Bumgardner K, Roy-Byrne P. Prediction of suicide ideation and attempt among substance-using patients in primary care. J Am Board Family Med. 2017;30(2):150.

18. Mugisha J, Hanlon C, Knizek BL, Ssebunnya J, Vancampfort D, Kinyanda E, Kigozi F. The experience of mental health service users in health system strengthening: lessons from Uganda. Int J Ment Heal Syst. 2019;13(1):60.

19. Wenzel A, Berchick ER, Tenhave T, Halberstadt S, Brown GK, Beck AT. Predictors of suicide relative to other deaths in patients with suicide attempts and suicide ideation: a 30-year prospective study. J Affect Disord. 2011;132(3):375-82.

20. Krysinska K, Lester D. Post-traumatic stress disorder and suicide risk: a systematic review. Arch Suicide Res. 2010;14(1):1-23.

21. Fortuna LR, A'Ivarez K, Ortiz RZ, Wang Y, Alegrı'a MX, Cook BL, Alegrı'a M. Mental health, migration stressors and suicidal ideation among Latino immigrants in Spain and the United States. Eur Psychiatry. 2016;36:15-22.

22. Sorsdahl K, Stein DJ, Williams DR, Nock MK. Associations between traumatic events and suicidal behavior in South Africa. J Nerv Ment Dis. 2011;199(12):928-33. 
23. Stein DJ, Chiu WT, Hwang I, Kessler RC, Sampson N, Alonso J, Borges G, Bromet E, Bruffaerts R, de Girolamo G, et al. Cross-national analysis of the associations between traumatic events and suicidal behavior: findings from the WHO World Mental Health Surveys. PLoS ONE. 2010;5(5):e10574.

24. Ovuga E, Boardman J, Wassermann D. Prevalence of suicide ideation in two districts of Uganda. Arch Suicide Res. $2005 ; 9(4): 321-32$.

25. Langhinrichsen-Rohling J, Friend J, Powell A. Adolescent suicide, gender, and culture: a rate and risk factor analysis. Aggress Violent Beh. 2009;14(5):402-14.

26. Goldston DB, Molock SD, Whitbeck LB, Murakami JL, Zayas LH, Hall GCN. Cultural considerations in adolescent suicide prevention and psychosocial treatment. Am Psychol. 2008;63(1):14-31.

27. Pottie K, Dahal G, Georgiades K, Premji K, Hassan G. Do first generation immigrant adolescents face higher rates of bullying, violence and suicidal behaviours than do third generation and native born? J Immigr Minor Health. 2015;17(5):1557-66.

28. UNHCR, OPM. Interagency assessment of measures, services and safeguards for the protection of women and children against sexual and gender-based violence. 2019. https://reliefweb.int/report/uganda/interagency-assessment-measures-services-and-safeguards-prote ction-womenand-children. Accessed 31 Jan 2021.

29. Joining forces coalition: keeping children safe in Uganda's COVID-19 response. 2020. https://reliefweb.int/report/uganda/keeping-child ren-safe-uganda-s-covid-19-response-may-2020. Accessed 31 Jan 2021.

30. Government of Uganda, World Bank. Gender-based violence and violence against children prevention and response services in Uganda's Refugee-Hosting Districts. 2020. https://openknowledge.worldbank.org/handle/10986/34494. Accessed 31 Jan 2021.

31. Chahine M, Salameh P, Haddad C, Sacre H, Soufia M, Akel M, Obeid S, Hallit R, Hallit S. Suicidal ideation among Lebanese adolescents: scale validation, prevalence and correlates. BMC Psychiatry. 2020;20(304):1-11.

32. Wilson ML, Dunlavy AC, Viswanathan B, Bovet P. Suicidal expression among school-attending adolescents in a middle-income sub-Saharan country. Int J Environ Res Public Health. 2012;9(11):4122-34.

33. George U, Thomson MS, Chaze F, Guruge S. Immigrant mental health, a public health issue: looking back and moving forward. Int J Environ Res Public Health. 2015;12(10):13624-48.

34. Gimeno-Feliu LA, Magallón-Botaya R, Macipe-Costa RM, Luzón-Oliver L, Cañada-Millan JL, Lasheras-Barrio M. Differences in the Use of Primary Care Services Between Spanish National and Immigrant Patients. J Immigr Minor Health. 2013;15:584-90.

35. World Bank. Informing the refugee policy response in Uganda: results from the Uganda refugee and host communities 2018 household survey. 2019. https://www.worldbank.org/en/news/factsheet/2019/10/01/informingthe-refugee-policy-response-in-uganda-resultsfrom-the-uganda-refugee-and-host-communities-2018-householdsurvey. Accessed 31 Jan 2021.

36. Crawford N, O'Callaghan S, Holloway K, Lowe C. The comprehensive refugee response framework: progress in Uganda. 2019. https:// www.odi.org/sites/odi.org.uk/files/resource-documents/12937.pdf. Accessed 31 Jan 2021.

37. Bohnet $\mathrm{H}$, Schmitz-Pranghe $\mathrm{C}$. Uganda: a role model for refugee integration? 2019.

38. Bukuluki P, Mwenyango H, Katongole SP, Sidhva D, Palattiyil G. The socio-economic and psychosocial impact of Covid-19 pandemic on urban refugees in Uganda. Soc Sci Hum Open. 2020;2(1):100045.

39. Joiner TE Jr, Brown JS, Wingate LR. The psychology and neurobiology of suicidal behavior. Annu Rev Psychol. 2005;56(1):287-314.

40. Forkmann T, Glaesmer H, Paashaus L, Rath D, Schönfelder A, Stengler K, Juckel G, Assion H-J, Teismann T. Interpersonal theory of suicide: prospective examination. BJPsych Open. 2020;6(5):e113.

41. Barzilay S, Feldman D, Snir A, Apter A, Carli V, Hoven CW, Wasserman C, Sarchiapone M, Wasserman D. The interpersonal theory of suicide and adolescent suicidal behavior. J Affect Disord. 2015;183:68-74.

42. Hadzic A, Spangenberg L, Hallensleben N, Forkmann T, Rath D, Strauß M, Kersting A, Glaesmer H. The association of trait impulsivity and suicidal ideation and its fluctuation in the context of the Interpersonal Theory of Suicide. Compr Psychiatry. 2020;98:152158.

43. De Beurs D, Fried El, Wetherall K, Cleare S, O'Connor DB, Ferguson E, O' Carroll RE, O'Connor RC. Exploring the psychology of suicidal ideation: a theory driven network analysis. Behav Res Ther. 2019;120:103419.

44. Macintyre VG, Mansell W, Pratt D, Tai SJ. The psychological pathway to suicide attempts: a strategy of control without awareness. Front Psychol. 2021;12:495.

45. Kuh D, Ben-Shlomo Y, Lynch J, Hallqvist J, Power C. Life course epidemiology. J Epidemiol Community Health. 2003;57(10):778-83.

46. Hua P, Maple M, Hay K, Bugeja L. Theoretical frameworks informing the relationship between parental death and suicidal behaviour: a scoping review. Heliyon. 2020;6(5):e03911.

47. Björkenstam C, Kosidou K, Björkenstam E. Childhood adversity and risk of suicide: cohort study of 548721 adolescents and young adults in Sweden. BMJ. 2017;357:j1334.

48. WHO. Ethical standards for research during public health emergencies: distilling existing guidance to support COVID-19 R\&D. 2020. https://apps.who.int/iris/handle/10665/331507. Accessed 31 Jan 2021.

49. Krejcie RV, Morgan DW. Determining sample size for research activities. Educ Psychol Meas. 1970;30(3):607-10.

50. Culbreth R, Swahn MH, Ndetei D, Ametewee L, Kasirye R. Suicidal Ideation among Youth Living in the Slums of Kampala, Uganda. Int J Environ Res Public Health. 2018;15(2):298.

Publisher's Note Springer Nature remains neutral with regard to jurisdictional claims in published maps and institutional affiliations. 